\title{
EFEITOS DE LÂMINAS DE ÁGUA E FERTIRRIGAÇÃO POTÁSSICA SOBRE O CRESCIMENTO, PRODUÇÃO E QUALIDADE DO TOMATE EM AMBIENTE PROTEGIDO
}

\author{
Effects of water nivels and potassium fertirrigation on growth, production and \\ quality of tomato fruits in greenhouse
}

\author{
Ladilson de Souza Macêdo ${ }^{1}$, Marco Antônio Rezende Alvarenga ${ }^{2}$
}

\begin{abstract}
RESUMO
Avaliaram-se os efeitos de lâminas de água e fertilização potássica sobre o crescimento e produção da cultura do tomate (Lycopersicon esculentum Mill.) híbrido Bônus $\mathrm{F}_{1}$, em ambiente protegido, num Latossolo Vermelho Distroférrico no Setor de Olericultura da Universidade Federal da Lavras, MG. Foram testadas as lâminas de água 40, 60, 80 e $100 \%$ Kc.Ev e as doses de $300,500,700$ e $900 \mathrm{~kg} \mathrm{ha}^{-1}$ de $\mathrm{K}_{2} \mathrm{O}$ (nitrato de potássio e cloreto de potássio). As fertirrigações foram iniciadas 10 dias após o transplantio, três vezes por semana, durante o ciclo da cultura, utilizando-se o sistema de irrigação por gotejamento. As lâminas de água aplicadas influenciaram o crescimento das plantas aos 30, 60 e 90 dias de idade, no entanto, não houve efeito da fertilização potássica e sua interação com lâmina de água nessas características e na produção dos frutos. O número de frutos comerciais Extra AAA, Extra AA e Extra A aumentou na proporção de 0,462; 0,681 e 1,038 frutos.planta ${ }^{-1}$, respectivamente, para cada $20 \% \mathrm{Kc}$.Ev de acréscimo sobre a lâmina de água aplicada. Brix e pectina aumentaram em função das lâminas de água até $100 \%$ $\mathrm{K}_{\mathrm{c}}$. $\mathrm{E}_{\mathrm{V}}$, enquanto Brix, acidez total e $\mathrm{pH}$ aumentaram em função das doses de potássio até $700 \mathrm{Kg} \cdot \mathrm{Ka}^{-1}$ de $\mathrm{K}_{2} \mathrm{O}$.
\end{abstract}

TERMOS PARA INDEXAÇÃO: tomateiro, Lycopersicon esculentum, fertirrigação, potássio, qualidade do fruto.

\begin{abstract}
The effects of water levels and potassium fertirrigation on plant growth, production and quality of the fruits of Bônus F1 hibrid tomatoes (Lycopersicom esculentum Mill.) were evaluated in protected environment, in the Horticulture Sector of the Universidade Federal de Lavras, Minas Gerais State, Brazil, with the plants growing on a Dystroferric Red Latosol. Drip irrigation was used at levels of 40,60, 80 and $100 \% \mathrm{Kc}$.Ev, with the dosages 300, 500, 700 and $900 \mathrm{~kg} \cdot \mathrm{ha}^{-1}$ of $\mathrm{K}_{2} \mathrm{O}$ (potassium nitrate and potassium chloride) being evaluated. Fertirrigations started 10 days after the transplanting and were done three times a week, during the cycle of the crop. The applied water levels influenced the plants growth at 30,60 and 90 days, with no effect of potassium fertilization and its interaction with the levels of irrigation on plant growth or on the fruits production being observed. The number of tradable fruits Extra AAA, Extra AA and Extra A increased at 0.462; 0.681 and 1.038 unities.plant $^{-1}$ for each $20 \%$ of increase on the level of irrigation. Brix and soluble pectine increased with the irrigation levels until $100 \% \mathrm{~K}_{\mathrm{c}} . \mathrm{E}_{\mathrm{v}}$ wheres Brix, acidity and $\mathrm{pH}$ increased with the potassium levels until $700 \mathrm{~kg} \cdot \mathrm{ha}^{-1}$ of $\mathrm{K}_{2} \mathrm{O}$.
\end{abstract}

INDEX TERMS: tomato, Lycopersicon esculentum, fertirrigation, potassium, quality of fruit.

(Recebido para publicação em 22 de novembro de 2002 e aprovado em 21 de agosto de 2003)

\section{INTRODUÇÃO}

O tomateiro é cultivado em todo mundo, com área plantada estimada em 2,7 milhões de hectares, e no Brasil, em cerca de 56,7 mil hectares (IBGE, 2002).

Dentre os fatores de produção, a água e os nutrientes são os que limitam o rendimento do tomateiro (Lycopersicon esculentum Mill.) com maior intensidade, o que requer controle eficiente da umidade do solo e da nutrição mineral, para se obter uma exploração comercial agrícola de altas qualidade e produtividade.
O potássio assume papel importante para a cultura do tomate, considerando sua atuação na síntese de carotenóides, (JOHJIMA, 1994), principalmente o licopeno, responsável pela cor vermelha do fruto, e também na biossíntese de açúcares, ácidos orgânicos, vitamina $\mathrm{C}$ e sólidos solúveis totais. Uma das características que destaca o tomate entre as outras hortaliças é sua alta eficiência de uso de água, em média, $11 \mathrm{~kg} \mathrm{~m}^{-3}$ (DOOREMBOS \& KASSAM, 1994), o que the proporciona alta produtividade (até $10 \mathrm{~kg}$ por planta), quando irrigado adequadamente.

1. Engenheiro Agrônomo, D.Sc., Embrapa/Empresa Estadual de Pesquisa Agropecuária da Paraíba S.A. (EMEPA-PB) - Caixa Postal 275 - 58.013-290 João Pessoa-PB - emepa@emepa.org.br

2. Engenheiro Agrônomo, Doutor - Professor Titular - Departamento de Agricultura - Universidade Federal de Lavras/UFLA, Caixa Postal 3037 - $37.200-000$ Lavras,MG - marcoalvarenga@ufla.br 
A fertirrigação localizada possibilita a aplicação em função das demandas hídrica e nutricional da planta, sendo o sistema de irrigação por gotejamento o mais utilizado no cultivo do tomateiro. Nos sistemas automatizados de irrigação, em estruturas de proteção, o uso de temporizador (irrigation controler) e válvulas solenóides têm facilitado o manejo eficaz e eficiente da fertirrigação.

Os trabalhos sobre fertirrigação no Brasil ainda são escassos e pouco divulgados; contudo, nos trabalhos existentes, verifica-se que essa técnica é bastante promissora, sendo imprescindível, entretanto, estudos que permitam melhor entendimento para equacionar as complexas interações existentes sobre a cinética de absorção de nutrientes ao longo do ciclo da cultura. Com a presente pesquisa teve-se como objetivo estudar os efeitos da aplicação de lâminas de água e doses de potássio, via fertirrigação por gotejamento, sobre o crescimento, a produção e a qualidade dos frutos do tomateiro sob ambiente protegido.

\section{MATERIAL E MÉTODOS}

O trabalho foi conduzido no Setor de Olericultura da Universidade Federal de Lavras (UFLA), no município de Lavras-MG $\left(21^{\circ} 14^{\prime} \mathrm{S}, 45^{\circ} 00^{\prime} \mathrm{W}\right.$. Gr. e $918,7 \mathrm{~m}$ de altitude), no período de setembro de 2001 a janeiro de 2002.

O solo da área experimental (Latossolo Vermelho Distrófico) apresentou as seguintes características de fertilidade à profundidade de $0 \mathrm{a} 20 \mathrm{~cm}$ : $\mathrm{pH}$ em água 5,8; Fósforo $29,0 \mathrm{mg} \mathrm{dm}^{-3}$; Potásio $137,0 \mathrm{mg} \mathrm{dm}^{-3}$; Cálcio $4,8 \mathrm{cmol}_{\mathrm{c}} \mathrm{dm}^{-3}$; Magnésio $1,6 \mathrm{cmol}_{\mathrm{c}} \mathrm{dm}^{-3}$; Alumínio $0,0 \mathrm{cmol}_{\mathrm{c}} \mathrm{dm}^{-3}$ e Matéria orgânica 3,2 dag kg ${ }^{-1}$. As análises foram realizadas pelo Laboratório de Fertilidade do Departamento de Ciência do Solo da UFLA.

$\mathrm{O}$ experimento foi realizado em casa-devegetação, do tipo capela e modelo de estrutura "Ana Dias" modificado (SOUZA et al., 1994), com $10 \mathrm{~m}$ de largura e $31 \mathrm{~m}$ de comprimento $\left(310 \mathrm{~m}^{2}\right)$, com pé direito de $2 \mathrm{~m}$ e altura da parte central de $3,5 \mathrm{~m}$, com cortinas laterais

O experimento constou de 64 canteiros de 2,00 $\mathrm{m}$ de comprimento e $1,20 \mathrm{~m}$ de largura, cada um com 10 plantas, sendo consideradas as duas centrais como plantas úteis. O delineamento foi o de blocos casualizados com arranjo de parcelas subdivididas. Nas parcelas principais, foram testadas quatro lâminas de água (40, $60,80$ e $100 \% \mathrm{Kc} . \mathrm{Ev})$ e, nas subparcelas, quatro níveis de $\mathrm{K}\left(300,500,700\right.$ e $\left.900 \mathrm{~kg} \mathrm{ha}^{-1}\right)$.

O transplantio foi realizado no dia $06 / 09 / 2001$, com os canteiros previamente umedecidos, estando as mudas com 27 dias e quatro pares de folhas, com cerca de $15 \mathrm{~cm}$ de altura e bem uniformes. Foi utilizado o híbrido F1 Bônus, no espaçamento de $0,60 \mathrm{~m}$ entre linhas e $0,40 \mathrm{~m}$ entre plantas.

O manejo da irrigação foi realizado com base na evapotranspiração diária de um minitanque, considerando o coeficiente do tanque $(\mathrm{K})$ igual a 1,0 , conforme recomendação de Prados (1986), citado por Evangelista (1999).

De acordo com Marouelli et al. (1996), a evapotranspiração da cultura $\left(\mathrm{ET}_{\mathrm{c}}\right)$ pode ser estimada indiretamente pela seguinte equação:

Em que:

$$
\mathrm{ET}_{\mathrm{c}}=\mathrm{Kt} \cdot \mathrm{Kc} \cdot \mathrm{Ev} .
$$

$\mathrm{ET}_{\mathrm{c}}=$ evapotranspiração da cultura $\left(\mathrm{mm} \cdot \mathrm{dia}^{-1}\right)$;

$\mathrm{Kt}=$ coeficiente do tanque, adimensional;

$\mathrm{Kc}=$ coeficiente da cultura, adimensional;

$\mathrm{Ev}=$ evaporação do tanque $\left(\mathrm{mm} \cdot \mathrm{dia}^{-1}\right)$.

Os valores de Kc utilizados nos diferentes estádios de desenvolvimento foram adaptados de Allen et al. (1998) e Marouelli et al. (1996, 2001), os quais são apresentados a seguir:

Estadio I - Do transplantio até $10 \%$ do desenvolvimento vegetativo $(0,60)$;

Estadio II - Desde o final da fase I até 70 a $80 \%$ do desenvolvimento vegetativo (início do florescimento) $(0,85)$;

Estadio III - Desde o final da fase II até o início da maturação $(1,15)$;

Estadio IV - Desde o final da fase III até o final da colheita $(0,90)$.

Assim, a lâmina de água a ser aplicada com uma freqüência diária foi calculada considerando-se a percentagem da $\mathrm{ET}_{\mathrm{c}}$, ou seja, Kc.Ev, de acordo com cada tratamento $(\mathrm{K})$ conforme a equação abaixo:

$$
\mathrm{La}=\mathrm{Kc} . \mathrm{Ev} \cdot \mathrm{K} .
$$

Em que:

$\mathrm{La}=$ lâmina de água a ser aplicada em cada tratamento $(\mathrm{mm})$

$\mathrm{Ev}=$ evaporação do minitanque $\left(\mathrm{mm} \cdot \mathrm{dia}^{-1}\right)$;

$\mathrm{Kc}=$ coeficiente da cultura, adimensional;

$\mathrm{K}=$ porcentagem da evapotranspiração, de acordo com o tratamento.

As diferentes lâminas de água, para cada tratamento, foram aplicadas em diferentes tempos de funcionamento das linhas de gotejadores dispostos nos canteiros, calculados em função da vazão média dos 
gotejadores e do espaçamento entre eles (ao longo da linha de água e entre linhas), conforme a seguinte equação:

$$
\mathrm{Ti}=\frac{L a \cdot S q \cdot S i}{q}
$$

Em que:

$\mathrm{Ti}=$ tempo de irrigação para cada tratamento $(\mathrm{h})$;

$\mathrm{La}=$ lâmina de água a ser aplicada no tratamento ( $\mathrm{mm})$;

$\mathrm{Sg}=$ espaçamento entre gotejadores na linha de irrigação (m);

$\mathrm{Si}=$ espaçamento entre linhas de irrigação (m);

$\mathrm{q}=$ vazão média do gotejador $\left(\mathrm{L} \cdot \mathrm{h}^{-1}\right)$.

Após determinadas as quantidades, os fertilizantes
(Tabela 1) foram pesados e, posteriormente, diluídos por 45 minutos, até suas injeções no sistema específico. Em seguida, programou-se o controlador do sistema irrigação/fertirrigação de acordo com os tempos descritos anteriormente.

O sistema de fertirrigação foi o gotejamento convencional, com adaptação do sistema de injeção da solução de fertilizantes tipo aplicação de soro hospitalar. O teste de vazão foi realizado em cada um dos 640 gotejadores instalados no sistema de fertirrigação, o qual indicou a substituição de vários deles, até que a vazão estivesse próxima à indicada pelo fabricante $\left(2,3 \mathrm{~L} \mathrm{~h}^{-}\right)$. Considerando-se essa vazão e 40 gotejadores por tratamento (10 plantas canteiro ${ }^{-}$ ${ }^{1}$ x 4 blocos), obteve-se uma vazão de $92 \mathrm{~L} \mathrm{~h}^{-1}$ em cada tratamento, ou seja, aproximadamente $1,5 \mathrm{~L} \mathrm{~min}^{-1}$.

TABELA 1 - Fertirrigação potássica utilizada durante as fases de desenvolvimento vegetativo do tomateiro híbridos. Bônus $F_{1}$.

\begin{tabular}{|c|c|c|c|c|c|c|c|c|}
\hline \multirow{2}{*}{$\begin{array}{l}\text { Fases } \\
\text { (dias) }\end{array}$} & \multirow{2}{*}{$\begin{array}{c}\text { Lâmina } \\
\text { (mm) }\end{array}$} & \multirow{2}{*}{$\begin{array}{l}\text { Doses de } \\
\text { Potássio } \\
\left(\mathbf{k g ~ h a}^{-1}\right)\end{array}$} & \multirow{2}{*}{$\begin{array}{c}\text { Relação } \\
\text { N/K }\end{array}$} & \multirow{2}{*}{$\begin{array}{c}\text { Necessidade } \\
\text { de Potássio } \\
\text { (\%) }\end{array}$} & \multicolumn{4}{|c|}{ Nutrientes (g. parc. FI $^{-1}$ ) } \\
\hline & & & & & $\mathrm{KNO}_{3}$ & $\mathrm{CO}\left(\mathrm{NH}_{2}\right)_{2}$ & KCl & $\mathrm{Ca}\left(\mathrm{NO}_{3}\right)_{2}$ \\
\hline & 37,3 & 300 & & & 1,82 & 1,87 & - & - \\
\hline I & 58,2 & 500 & & & 3,00 & 1,50 & - & - \\
\hline \multirow[t]{3}{*}{ (40 dias) } & 77,7 & 700 & $1: 1$ & 20 & 4,20 & 1,12 & - & - \\
\hline & 97,1 & 900 & & & 5,45 & 0,75 & - & - \\
\hline & 73,9 & 300 & & & 2,73 & 2,80 & - & - \\
\hline II & 110,9 & 500 & & & 4,54 & 2,24 & - & - \\
\hline \multirow[t]{3}{*}{ (40 dias) } & 147,9 & 700 & $1: 1,5$ & 30 & 6,36 & 1,68 & - & - \\
\hline & 184,8 & 900 & & & 8,18 & 1,13 & - & - \\
\hline & 46,9 & 300 & & & - & 3,24 & 3,45 & 8,00 \\
\hline III & 70,4 & 500 & & & - & 3,24 & 5,74 & 8,00 \\
\hline \multirow[t]{2}{*}{ (42 dias) } & 93,8 & 700 & $1: 2$ & 50 & - & 3,24 & 8,01 & 8,00 \\
\hline & 117,3 & 900 & & & - & 3,24 & 10,34 & 8,00 \\
\hline
\end{tabular}

FI - fertirrigação; $\mathrm{KNO}_{3}\left(44 \% \mathrm{~K}_{2} \mathrm{O} ; 13 \% \mathrm{~N}\right) ; \mathrm{CO}\left(\mathrm{NH}_{2}\right)_{2}(44 \% \mathrm{~N}) ; \mathrm{Ca}\left(\mathrm{NO}_{3}\right)_{2}(15,5 \% \mathrm{~N}, 19 \% \mathrm{Ca})$

$\mathrm{L}_{1}=40 \% \mathrm{Kc} \mathrm{Ev} ; \mathrm{L}_{2}=60 \% \mathrm{Kc} \mathrm{Ev} ; \mathrm{L}_{3}=80 \% \mathrm{Kc}$ Ev e $\mathrm{L}_{4}=100 \% \mathrm{Kc} \mathrm{Ev}$

Fase I: Transplantio a início de floração $(13 / 09$ a 23/10/2001) $(\mathrm{Kc}=0,80)$

Fase II: Início de floração a início de colheita $(23 / 10$ a 03/12/2001) $(\mathrm{Kc}=1,15)$

Fase III: Início de colheita a final de colheita $(03 / 12 / 2001$ a 13/01/2002) $(\mathrm{Kc}=0,90)$ 
A produção total dos frutos resultou da soma do peso da matéria fresca dos frutos das 16 colheitas realizadas, expressa em kg. planta ${ }^{-1}$. Os frutos foram separados por classe, de acordo com o seu diâmetro: Extra AAA $(\Phi \geq 60 \mathrm{~mm})$; Extra AA $(56 \leq \Phi<60 \mathrm{~mm})$; Extra A $(47 \leq \Phi<56)$. Os frutos rachados, descoloridos, defeituosos ou com diâmetro abaixo de $47 \mathrm{~mm}$ foram considerados não-comercializáveis.

As variáveis de crescimento (comprimento de plantas aos 30,60 e 90 dias de idade) e de produção foram submetidas à análise de variância com regressão e as variáveis acidez total, pectina total, pectina solúvel, Brix e $\mathrm{pH}$ foram submetidas à análise estatística, obedecendo a um esquema de análise de variância com regressão polinominal para um arranjo fatorial $4 \times 4$, sem repetições. Nesse caso, foi usada a interação dupla L x K como resíduo, de acordo com Pimentel-Gomes (1985). Os dados referentes a número de frutos doentes (podridão apical) e número de frutos não-comerciais foram previamente transformados em $\sqrt{X}$ e o número de frutos sadios e número de frutos comerciais (Extra AAA, Extra AA e Extra A) foram convertidos em $\sqrt{X+1}$ e submetidos à análise de variância (STEEL \& TORRIE, 1960; PIMENTEL-GOMES, 1985).

\section{RESULTADOS E DISCUSSÃO}

\section{Comprimento de plantas aos 30, 60 e 90 dias}

$\mathrm{Na}$ Tabela 2 verifica-se que houve efeito linear significativo a 0,05 de probabilidade de lâminas de água sobre o crescimento de plantas aos 30 dias de idade e a 0,01 de probabilidade sobre o comprimento de plantas aos 60 e 90 dias. Não houve influência significativa $(\mathrm{P}>0,05)$ da fertilização com potássio nem efeito interativo entre lâminas de água e doses de potássio sobre o crescimento de plantas até 90 dias de idade.

O comportamento linear do crescimento do tomateiro, em termos de comprimento de plantas aos 30 dias, em função das lâminas de água aplicadas, foi expresso pela equação $\mathrm{Y}=53,3662+11,1034 \mathrm{X}, \mathrm{R}^{2}=$ $74,91 \%(\mathrm{P}<0,05)$, sendo $\mathrm{Y}=$ comprimento dos pontos aos 30 dias e $\mathrm{X}=$ Lâminas de água aplicadas. Aos 60 e 90 dias, as equações foram $\mathrm{Y}=127,7999+34,5941 \mathrm{X}$, $\mathrm{R}^{2}=84,32 \%(\mathrm{P}<0,01)$, sendo $\mathrm{Y}=$ comprimento dos pontos aos 60 dias e $\mathrm{X}=$ Lâminas de água aplicadas; e $\mathrm{Y}=153,6031+26,2031 \mathrm{X}, \mathrm{R}^{2}=86,41 \%(\mathrm{P}<0,01)$, sendo $\mathrm{Y}=$ comprimento dos pontos aos 90 dias e $\mathrm{X}=$ Lâminas de água aplicadas, respectivamente.

TABELA 2 - Resumo das análises de variância para comprimento de plantas de tomateiro aos 30, 60 e 90 dias de idade, submetido a diferentes lâminas de água e fertilização potássica, em casa-de-vegetação.

\begin{tabular}{lccccccc}
\hline \multirow{2}{*}{ Fontes de variação } & GL & \multicolumn{7}{c}{ Quadrados Médios } \\
\cline { 3 - 9 } & & \multicolumn{2}{c}{ CP30 } & \multicolumn{1}{c}{ CP60 } & CP90 & \\
\hline Blocos & 3 & 162,3845 & ns & 421,2803 & $\mathrm{~ns}$ & 415,3893 & $\mathrm{~ns}$ \\
Lâminas = L & 3 & 175,5530 & $* * *$ & 1513,9373 & $*$ & 847,5768 & $*$ \\
Linear & 1 & 394,5162 & $*$ & 3829,5973 & $* *$ & 2197,1320 & $* *$ \\
Desvio da reg. & 2 & 66,0714 & $\mathrm{~ns}$ & 326,1073 & $\mathrm{~ns}$ & 172,7993 & $\mathrm{~ns}$ \\
Resíduo (a) & 9 & 53,4766 & & 371,3948 & & 143,6636 & \\
Potássio = K & 3 & 82,1259 & $\mathrm{~ns}$ & 681,5964 & $\mathrm{~ns}$ & 283,7227 & $\mathrm{~ns}$ \\
Interação L x K & 9 & 27,6792 & $\mathrm{~ns}$ & 701,1546 & $\mathrm{~ns}$ & 225,6775 & $\mathrm{~ns}$ \\
Resíduo (b) & 36 & 44,7746 & & 1221,6889 & & 573,3312 & \\
\hline CV (a) \% & - & 11,96 & & 12,68 & & 6,97 & \\
CV (b) \% & - & 10,94 & & 22,99 & & 14,93 & \\
\hline
\end{tabular}

* e ** (Significativo a 5\% e 1\% de probabilidade, respectivamente, pelo teste $\mathrm{F}$ )

$* * *$ Significativo $(\mathrm{P}>0,0724)$

ns (Não-significativo) 


\section{Número de frutos comerciais}

Houve efeito linear significativo $(\mathrm{P}<0,01)$ de lâminas de água sobre o número de frutos comerciais tipos Extra AAA, ExtraAA e ExtraA (Tabela 3). Esse resultado concorda com Nannetti (2001) e Santos et al. (1998). Já Cook \& Sanders (1991) e Oliveira et al. (1980) observaram aumento significativo com a utilização de K somente na produção de frutos graúdos.

$\mathrm{O}$ total do rendimento comercial aumentou somente devido à maior freqüência de frutos grandes. Carrijo et al. (1996), estudando o potássio fornecido em fertirrigação por gotejamento para o tomateiro cv. Irazu (grupo salada), em ambiente protegido, conseguiram obter maior produtividade quando utilizaram 10,8 $\mathrm{g} \mathrm{planta}^{-1}$ de $\mathrm{K}_{2} \mathrm{O}$ e melhores frutos com 17,6 $\mathrm{g} \mathrm{K}_{2} \mathrm{O}$ planta $^{-1}$.

Não foi observado efeito significativo $(\mathrm{P}>0,05)$ de doses de fertilização potássica e da interação lâminas de água $\mathrm{x}$ doses de potássio sobre o número de frutos comerciais (Tabela 3 ).

As equações de regressão para número de frutos comerciais tipo Extra AAA, Extra AA e Extra A foram: $\mathrm{Y}$ $=-0,5406+2,3125 \mathrm{X}, \mathrm{R}^{2}=80,85 \%(\mathrm{P}<0,05) ; \mathrm{Y}=-0,4469$ $+3,4062 X, R^{2}=76,72 \%(P<0,01)$ e $Y=2,275+5,1875 X$,
$\mathrm{R}^{2}=82,19 \%(\mathrm{P}<0,01)$, respectivamente, sendo $\mathrm{Y}=$ número de frutos comerciais e $\mathrm{X}=$ Lâmina de água.

Observando-se ainda a Tabela 3, constata-se que lâminas de água, fertilização potássica e interação lâminas de água $\mathrm{x}$ fertilização potássica não exerceram influência significativa $(\mathrm{P}>0,05)$ sobre o número de frutos não-comerciais.

\section{Peso de frutos doentes, sadios e total}

Pela Tabela 4 constata-se que houve efeito linear significativo $(\mathrm{P}<0,05)$ de lâminas de água apenas sobre o peso dos frutos sadios e peso dos frutos total. As doses de potássio não influenciaram significativamente $(\mathrm{P}>0,5)$ os pesos de frutos doentes, sadios e total, assim como a interação lâmina x potássio. Esses resultados estão de acordo com Boaretto et al. (1983) e Takahashi (1993), os quais afirmam que, embora o tomateiro seja exigente em potássio, não é freqüente observar respostas de produção com a aplicação desse elemento no solo. Este fato pode estar relacionado aos altos teores iniciais de potássio no solo da área experimental, proveniente de resíduos de adubações efetuadas em experimentos que precederam o ensaio em questão.

TABELA 3 - Resumo das análises de variância para número de frutos comerciais tipos Extra AAA (NFEAAA), Extra AA (NFEAA) e Extra A (NFEA) de tomateiro, submetido a diferentes lâminas de água e fertilização potássica, em casa-de-vegetação.

\begin{tabular}{lcccccccc}
\hline \multirow{2}{*}{ Fontes de variação } & GL & \multicolumn{7}{c}{ Quadrados Médios } \\
\cline { 3 - 9 } & & NFEAAA & & NFEAA & & NFEA \\
\hline Blocos & 3 & 0,1419 & $\mathrm{~ns}$ & 0,2237 & $\mathrm{~ns}$ & 3,5774 & $*$ \\
Lâminas = L & 3 & 1,6435 & $*$ & 3,1945 & $*$ & 4,7863 & $* *$ \\
Linear & 1 & 3,9864 & $* *$ & 7,3522 & $* *$ & 11,8017 & $* *$ \\
Desvio da reg. & 2 & 0,4721 & $\mathrm{~ns}$ & 1,1157 & $\mathrm{~ns}$ & 1,2786 & $\mathrm{~ns}$ \\
Resíduo (a) & 9 & 0,3025 & & 0,4725 & & 0,5943 & \\
Potássio = K & 3 & 0,0297 & $\mathrm{~ns}$ & 0,3549 & $\mathrm{~ns}$ & 2,1888 & $\mathrm{~ns}$ \\
Interação L x K & 9 & 0,7312 & $\mathrm{~ns}$ & 1,4752 & $\mathrm{~ns}$ & 2,6053 & $\mathrm{~ns}$ \\
Resíduo (b) & 36 & 0,6625 & & 0,9767 & & 2,7986 & \\
\hline CV (a) \% & - & 34,42 & & & 34,92 & & 24,03 & \\
CV (b) \% & - & 50,94 & & 50,21 & & 52,14 & \\
\hline
\end{tabular}

* e** (Significativo a 5\% e 1\% de probabilidade, respectivamente, pelo teste $\mathrm{F}$ )

ns (Não-significativo)

Dados transformados em $\sqrt{X+1}$ 
TABELA 4 - Resumo das análises de variância para pesos de frutos doentes (PFD), sadios (PFS) e total (PFT) de tomateiro, submetido a diferentes lâminas de água e fertilização potássica, em casa-de-vegetação.

\begin{tabular}{|c|c|c|c|c|c|c|c|}
\hline \multirow{3}{*}{$\begin{array}{l}\text { Fontes de variação } \\
\text { Blocos }\end{array}$} & \multirow{3}{*}{$\frac{\mathbf{G L}}{3}$} & \multicolumn{6}{|c|}{ Quadrados Médios } \\
\hline & & \multicolumn{2}{|c|}{ PFD } & \multicolumn{2}{|c|}{ PFS } & \multicolumn{2}{|c|}{ PFT } \\
\hline & & 0,4889 & ns & 0,6031 & ns & 1,7981 & ns \\
\hline Lâminas = L & 3 & 0,3245 & ns & 5,4779 & $*$ & 8,2872 & $*$ \\
\hline Linear & 1 & 0,9504 & $\mathrm{~ns}$ & 13,7262 & $* *$ & 21,9053 & $* *$ \\
\hline Desvio da reg. & 2 & 0,0115 & $\mathrm{~ns}$ & 1,3537 & ns & 1,4781 & ns \\
\hline Resíduo (a) & 9 & 0,2760 & & 0,8609 & & 1,5410 & \\
\hline Potássio $=\mathrm{K}$ & 3 & 0,0671 & $\mathrm{~ns}$ & 3,1920 & $\mathrm{~ns}$ & 3,0544 & $\mathrm{~ns}$ \\
\hline Interação L x K & 9 & 0,1876 & $\mathrm{~ns}$ & 2,6718 & $\mathrm{~ns}$ & 2,8923 & $\mathrm{~ns}$ \\
\hline Resíduo (b) & 36 & 0,3650 & & 2,9585 & & 4,4990 & \\
\hline CV (a) $\%$ & - & 47,52 & & 41,89 & & 37,39 & \\
\hline CV (b) $\%$ & - & 54,65 & & 77,67 & & 63,88 & \\
\hline
\end{tabular}

* e ** (Significativo a 5\% e 1\% de probabilidade, respectivamente, pelo teste $\mathrm{F}$ ) ns (Não-significativo)

Pela análise de regressão, verificou-se que o peso de frutos sadios e peso de frutos total de tomateiro apresentaram respostas lineares $(\mathrm{P}<0,01)$, com o aumento das lâminas de água, cujas equações foram: $\mathrm{Y}=$ $0,3824+1,0355 \mathrm{X}, \mathrm{R}^{2}=83,52 \%$ e $\mathrm{Y}=0,7445+1,3082$ $\mathrm{X}, \mathrm{R}^{2}=88,11 \%$, respectivamente, em que $\mathrm{Y}$ representa o peso de fruto planta ${ }^{-1} \mathrm{e} X$, as lâminas de água.

Um dos principais efeitos da cobertura plástica na proteção à cultura é a diminuição da demanda evaporativa em função das menores radiação solar e vento, fatores importantes, entre outros, que influenciam a evapotranspiração.

Durante o período de execução deste ensaio, a evaporação diária foi, em média, $3,34 \mathrm{~mm}$ considerada baixa para viabilizar o manejo da fertirrigação preconizado com freqüência de 3 dias por semana, com gotejador de baixa vazão $\left(2,3 \mathrm{~L} \cdot \mathrm{h}^{-1}\right)$.

Esses fatos parecem ter influenciado a disponibilidade dos nutrientes aplicados, haja vista que o tempo de irrigação (tempo de aplicação + tempo de fertirrigação + tempo de lavagem), na maioria das vezes, foi inferior a 30 minutos, o que dificultou a uniformidade de distribuição dos fertilizantes potássicos durante todo o ciclo da cultura.
Com relação às características químicas dos frutos (Tabela 5), verifica-se que o Brix aumentou discretamente com o aumento da interação da lâmina $80 \%$ $\mathrm{KcEv}$ com a dose de $700 \mathrm{KgK}_{2} \mathrm{Oha}^{-1}$.

Sampaio (1996) e Sampaio \& Fontes (1998), testando várias doses de $\mathrm{K}_{2} \mathrm{O}$ em fertirrigação do tomateiro, não observaram efeito significativo nos sólidos solúveis em frutos.

A presença de ácido cítrico nos frutos foi menos acentuada quando se aumentaram as lâminas de água e as doses de $\mathrm{K}_{2} \mathrm{O}$ no solo. Porém, as diferenças não foram expressivas, mostrando pequena influência dos tratamentos no conteúdo de ácidos nos frutos do tomateiro, o que está de acordo com Sampaio \& Fontes (1998). Elkner \& Kaniszewski (1993) e Moral et al. (1996) não encontraram efeito de fertilizantes químicos sobre os teores de ácido cítrico em frutos do tomateiro.

Segundo Panagiotopoulus \& Fordham (1995), frutos do tomateiro com teores de ácido cítrico abaixo de $0,44 \%$ são considerados insípidos. O "flavor" está relacionado principalmente com os açúcares $\left({ }^{\circ}\right.$ Brix) e ácidos e suas interações. Nesse caso, quanto maior o teor de açúcar e de ácido, melhor o sabor do fruto (GRIERSON \& KADER, 1986). 
TABELA 5 - Características químicas dos frutos de tomateiro, em função dos tratamentos fatoriais entre lâminas de água e doses de potásssio.

\begin{tabular}{cccccc}
\hline & & \multirow{2}{*}{$\begin{array}{c}\text { Acidez } \\
\text { Tratamentos }\end{array}$} & pH & $\begin{array}{c}\text { Sólidos Solú- } \\
\text { veis (\%) }\end{array}$ & \multicolumn{2}{c}{$\begin{array}{c}\text { Pectina } \\
\text { (mo ác. cítrico) }\end{array}$} & & Total * & Solúvel ** \\
\cline { 5 - 6 } & & & 4,40 & 690,43 & 204,59 \\
$\mathrm{~L}_{1} \mathrm{~K}_{1}$ & 4,01 & 0,26 & 4,10 & 697,28 & 190,64 \\
$\mathrm{~L}_{1} \mathrm{~K}_{2}$ & 4,09 & 0,24 & 4,70 & 704,73 & 199,30 \\
$\mathrm{~L}_{1} \mathrm{~K}_{3}$ & 3,90 & 0,28 & 4,40 & 649,25 & 194,09 \\
$\mathrm{~L}_{1} \mathrm{~K}_{4}$ & 4,00 & 0,28 & 4,10 & 645,47 & 148,11 \\
$\mathrm{~L}_{2} \mathrm{~K}_{1}$ & 4,00 & 0,26 & 4,20 & 640,98 & 144,25 \\
$\mathrm{~L}_{2} \mathrm{~K}_{2}$ & 4,03 & 0,22 & 5,00 & 630,04 & 147,57 \\
$\mathrm{~L}_{2} \mathrm{~K}_{3}$ & 4,00 & 0,28 & 4,80 & 656,81 & 167,45 \\
$\mathrm{~L}_{2} \mathrm{~K}_{4}$ & 4,02 & 0,28 & 4,90 & 633,72 & 170,05 \\
$\mathrm{~L}_{3} \mathrm{~K}_{1}$ & 4,09 & 0,26 & 5,30 & 686,44 & 178,53 \\
$\mathrm{~L}_{3} \mathrm{~K}_{2}$ & 4,07 & 0,26 & 5,50 & 632,29 & 172,07 \\
$\mathrm{~L}_{3} \mathrm{~K}_{3}$ & 4,08 & 0,28 & 5,20 & 665,95 & 180,77 \\
$\mathrm{~L}_{3} \mathrm{~K}_{4}$ & 4,09 & 0,27 & 4,70 & 631,17 & 203,54 \\
$\mathrm{~L}_{4} \mathrm{~K}_{1}$ & 4,02 & 0,27 & 4,80 & 643,64 & 204,74 \\
$\mathrm{~L}_{4} \mathrm{~K}_{2}$ & 4,02 & 0,29 & 5,80 & 678,58 & 191,61 \\
$\mathrm{~L}_{4} \mathrm{~K}_{3}$ & 4,02 & 0,28 & 4,60 & 657,43 & 191,03 \\
$\mathrm{~L}_{4} \mathrm{~K}_{4}$ & 4,04 & 0,28 & & & \\
\hline
\end{tabular}

* 5g. $100 \mathrm{~mL}^{-1}-1 \mathrm{~mL}^{-1} \cdot 10 \mathrm{~mL}^{-1}-0,5 \mathrm{~mL}$ Deter

** $5 \mathrm{~g} .50 \mathrm{~mL}^{-1}-1 \mathrm{~mL}^{-1} .10 \mathrm{~mL}^{-1}-1,0 \mathrm{~mL}$ Deter

Os valores de $\mathrm{pH}$ situam-se abaixo de 4,5 , limite estabelecido para separar frutos ácidos de não-ácidos (GOULD, 1974). O pH baixo é mais importante para o processo industrial, em face da inibição do crescimento de bactérias.

As diferenças nos valores de pectina solúvel e total são consideradas normais e expressivas. $\mathrm{O}$ maior teor de pectina solúvel $(204,74 \mathrm{mg} / 100 \mathrm{~g})$ foi verificado no tratamento de lâmina de $100 \% \mathrm{KcEv}$ e dose de $500 \mathrm{~kg} \mathrm{~K}_{2} \mathrm{O} \mathrm{ha}^{-1}$, e o menor valor $(144,25 \mathrm{mg} / 100 \mathrm{~g})$ no tratamento de $80 \%$ $\mathrm{KcEv}$ com a dose de $500 \mathrm{~kg} \mathrm{~K}_{2} \mathrm{O}$ há ${ }^{-1}$.

As oscilações ocorridas no conteúdo de pectina total ocorridas podem ser reflexos do metabolismo dinâmico das pectinas na parede celular, pois elas se degradam e se formam durante o amadurecimento dos frutos.

Diante do exposto, provavelmente o manejo da fertirrigação afetou o desempenho da aplicação de potássio e sua interação com as lâminas de água estudadas sobre as variáveis avaliadas.

Constatou-se efeito cúbico de lâminas de água sobre pectina solúvel e sólidos solúveis totais ( ${ }^{\circ}$ Brix), cujas equações de regressão foram: $\mathrm{Y}=774,055-$ $2602,4917 \mathrm{X}+3483,5625 \mathrm{X}^{2}-1457,3958 \mathrm{X}^{3}, \mathrm{R}^{2}$ $=100 \%(\mathrm{P}<0,03)$ e $\mathrm{Y}=11,975-39,6042 \mathrm{X}+64$, $375 X^{2}-31,770 X^{3}, R^{2}=100 \%(P<0,03)$, respectivamente, sendo $\mathrm{Y}=$ pectina solúvel ou brix e $\mathrm{X}=$ Lâminas de água. Do mesmo modo, constatou-se efeito cúbico de doses de potássio sobre acidez total, sólidos solúveis totais $\left({ }^{\circ}\right.$ Brix $)$ e $\mathrm{pH}$, cujas equações foram: $\mathrm{Y}=0,4955-0,001423 \mathrm{X}+0,0000025781$ $\mathrm{X}^{2}-0,0000000014 \mathrm{X}^{3}, \mathrm{R}^{2}=100 \%(\mathrm{P}<0,07) ; \mathrm{Y}=$ $9,2641-0,03089 \mathrm{X}+0,000061094 \mathrm{X}^{2}-$ $0,000000036 \mathrm{X}^{3}, \mathrm{R}^{2}=100 \%(\mathrm{P}<0,02)$ e $\mathrm{Y}=$ $3,4947-0,0033 \mathrm{X}+0,00006094 \mathrm{X}^{2}-0$, $000000003 \mathrm{X}^{3}, \mathrm{R}^{2}=100 \%(\mathrm{P}<0,09)$, respectivamente, sendo $\mathrm{Y}=$ acidez, brix ou $\mathrm{pH}$ e $\mathrm{X}=$ doses de potássio.

\section{CONCLUSÕES}

a) O número de frutos comerciais tipo Extra AAA, Extra AA e Extra A do tomateiro híbrido. Bônus 
F1 aumenta na proporção de 0,$462 ; 0,681$ e 1,038 frutos.planta ${ }^{-1}$, respectivamente, para cada $20 \% \mathrm{Kc}$. Ev de acréscimo sobre a lâmina de água aplicada à cultura.

b) A fertirrigação com potássio isolada e em interação com lâminas de água não influenciou as características de crescimento das plantas e de produção dos frutos, havendo, entretanto, a necessidade de novos estudos de fertilização potássica com menor freqüência de fertirrigação e maiores intervalos entre lâminas de água em solos com baixo teor de potássio.

c) As aplicações de lâminas de água e da fertilização potássica não exerceram influência, nem isoladamente nem em conjunto, sobre o número de frutos não comerciais;

d) As características Brix e pectina aumentaram em função das lâminas de água até $100 \% \mathrm{Kc}$.Ev, enquanto Brix, acidez total e $\mathrm{pH}$ aumentaram em função das doses de potássio até $700 \mathrm{~kg}^{-1}$ de $\mathrm{K}_{2} \mathrm{O}$.

\section{REFERÊNCIAS BIBLIOGRÁFICAS}

ALLEN, R. G.; PEREIRA, L. S.; RAES, D.; SMITH, N. Crop evapotranspiration: guidelines for computing crop water requeriments. Roma: FAO, 1998, 328 p. (Irrigation and drainage, papers, 56).

BOARETTO, A. E.; BULL, L. T.; PIERI, J. C.; CHITOLINA, J. C.; SOARES, E. Doses de potássio na adubação do tomateiro (Lycopersicon esculentum Mill.) estaqueado. Revista Agropecuária, Piracicaba, v. 58, p. 209-212, 1983.

CARRIJO, O. A.; MAKISHIMA, N.; OLIVEIRA, C. A. S.; REIS, N. V. B.; FONTES, R. Fatores de evapotranspiração do tanque Classe A e níveis de fertirrigação com nitrogênio e potássio afetando o cultivo protegido de tomate: resumo. Horticultura Brasileira, Brasília, DF, v. 14, n. 1, p. 78, maio, 1996.

COOK, W. P.; SANDERS, D. C. Nitrogen aplication frequency for drip-irrigated tomatoes. HortScience, Mont Vernon, v. 26, n. 3, p. 250-252, 1991.

DOOREMBOS, J.; KASSAM, A. H. Efeito da água no rendimento das culturas. Tradução de H. R. Gheyi, A. A. de Souza, F. A. V. Damasceno, J. F. de Medeiros. Campina Grande, PB: UFPB, 1994. 306 p. (Estudos FAO: Irrigação e Drenagem, 33).

EVAngelista, A. W. P. Avaliação de métodos de determinação da evapotranspiração no interior da casa de vegetação em Lavras-MG. 1999. 79 f.
Dissertação (Mestrado em Irrigação e Drenagem) Universidade Federal de Lavras, Lavras, 1999.

ELKNER, K.; KANISZEWSKI, S. Effect of drip irrigation and mulching on quality of tomato fruits. Acta Horticulturae, The Hague, v. 379, p. 349-354, 1993.

GOULD, W. A. Tomato production, processing and quality evaluation. Westport: The AVI, 1974. 445 p.

GRIERSON, D.; KADER, A. A. Fruit ripening and quality. In: ATHERTON, J. G.; RUDICH, J. (Eds.). The tomato crop: a scientific basis for improvement. London: Chapman and Hall, 1986. cap. 6, p. 241-280.

INSTITUTO BRASILEIRO DE GEOGRAFIA E ESTATÍSTICA. Levantamento sistemático da produção agrícola. Rio de Janeiro, 2002.

JOHJIMA, T. Carotene synthesis and caloring $\mathrm{n}$ tomato of various genotypic lines. Journal of the Japanese Society for Horticultural Science, Kioto, v. 63, n. 1, p. 109-114, 1994.

MAROUELLI, W. A.; SILVA, W. L. C.; SILVA, H. R. Irrigação por aspersão em hortaliças: qualidade da água, aspectos do sistema e método prático de manejo. Brasília: Embrapa Hortaliças, 2001. 111 p.

MAROUELli, W. A.; SILVA, W. L. C.; SILVA, H. R. Manejo da irrigação em hortaliças. 5. ed. Brasília, DF: EMBRAPA-SPI, 1996. 72 p.

MORAL, R.; NAVARRO PEDREND, J.; GOMEZ, U.; PALACIOS, G.; MATAIX, J. Tomato fruit yield and quality are affected by organic and inorganic fertilization and cadmium pollution. Journal of Plant Nutrition, Monticello, v. 19, n. 12, p. 1493-1498, 1996.

NANNETTI, D. C. Nitrogênio e potássio aplicados via fertirrigação na produção, nutrição e póscolheita do pimentão. 2001. 184 p. Tese (Doutorado em Agronomia/Fitotecnia) - Universidade Federal de Lavras, Lavras, 2001.

OLIVEIRA, C. A. S.; CARRIJO, O. A.; OLITTA, F. L.; REIS, N. V. B.; FONTES, R. R. Irrigação por gotejamento e fertirrigação de $\mathrm{N}$ e $\mathrm{K}$ em tomateiro. In: SEMINÁRIO LATINO-AMERICANO SOBRE RIEGO POR GOTEO, 3., 1979, Campinas. Informe final... San Jose: IICA, 1980. p. 476-490. 
PANAGIOTOPOULUS, L. J.; FORDHAM, R. Effects of water stress and potassium fertilization on yield and quality (flavour) of table tomatos (Lycopersicon esculentum Mill. L.). Acta Horticulturae, The Hague, v. 379, p. 113-120, 1995.

PIMENTEL-GOMES, F. Curso de estatística experimental. 11. ed. rev. e ampl. São Paulo: Nobel, 1985. $466 \mathrm{p}$.

SAMPAIO, R. A. Produção, qualidade dos frutos e teores de nutrientes no solo e no pecíolo do tomateiro em função da fertirrigação potássica e da cobertura plástica do solo. 1996. 117 f. Tese (Doutorado em Fitotecnia) - Universidade Federal de Viçosa, Viçosa, 1996.

SAMPAIO, R. A.; FONTES, P. C. R. Qualidade de frutos de tomateiro fertirrigado com potássio no solo coberto com polietileno preto. Horticultura Brasileira, Brasília, v. 16, n. 2, p. 136-139, nov. 1998.
SANTOS, R. F.; KLAR, A. E.; BRAGA, M. B. Efeitos da aplicação de N-K em irrigação por gotejamento na produção de pimentão (Capsicum annuum L.) em estufa de polietileno. In: CONGRESSO BRASILEIRO DE ENGENHARIA AGRÍCOLA, 27., 1998, Poços de Caldas, MG. Anais... Poços de Caldas: ABID, 1998.

SOUZA, J. A. de; SOUSA, R. J. de; COLLICCHIO, E.; GOMES, L. A. A.; SANTOS, H. S. Instruções práticas para a construção da estufa "Modelo Ana Dias". Lavras: UFLA, 1994. 20 p. (Boletim técnico).

STEEL, R. G. D.; TORRIE, J. H. Principles and procedures of statistics. New York: McGraw-Hill, 1960. $481 \mathrm{p}$.

TAKAHASHI, H. W. Nutrição e adubação de tomate estaqueado. In: SIMPÓSIO SOBRE NUTRIÇÃO E ADUBAÇÃO DE HORTALIÇAS, 1990, Jaboticabal. Anais... Piracicaba: POTAFOS, 1993. p. 301-322. 